\title{
Energetic cost of digging behavior in workers of the leaf-cutting ant Atta sexdens (Fabricius)
}

\author{
Roberto da Silva Camargo ${ }^{1}$, Juliane F. S. Lopes ${ }^{1} \&$ Luiz Carlos Forti ${ }^{2}$
}

\author{
${ }^{1}$ Mirmecolab, Universidade Federal de Juiz de Fora, Instituto de Ciências Biológicas. \\ Rua José Lourenço Kelmer, s/n - Campus Universitário, Bairro São Pedro, 36036-900 Juiz de Fora-MG, Brazil. camargobotucatu@yahoo.com.br \\ ${ }^{2}$ Laboratório de Insetos Sociais-Praga, Departamento de Produção Vegetal, Faculdade de Ciências Agronômicas/UNESP, P.O. Box 237, \\ 18603-970 Botucatu-SP, Brazil.
}

\begin{abstract}
Energetic cost of digging behavior in workers of the leaf-cutting ant Atta sexdens (Fabricius). During nest excavation, leaf-cutting ant workers undergo reduction in their body reserve, particularly carbohydrates. In order to estimate the energetic cost of digging, groups of 30 workers of the leaf-cutting ant Atta sexdens were sealed in a hermetic chamber for 24, 48 and 72 hours, with and without soil for digging, and had the $\mathrm{CO}_{2}$ concentration measured using respirometric chambers as well as volume of soil excavated (g). As expected, the worker groups that carried out soil excavation expelled more carbon dioxide than the groups that did not excavate. Therefore, a worker with body mass of $9.65 \pm 1.50 \mathrm{mg}$ dug in average $0.85 \pm 0.27 \mathrm{~g}$ of soil for 24 hours, consuming ca. $0.58 \pm 0.23 \mathrm{~J}$. In this study, we calculate that the energetic cost of excavation per worker per day in the experimental set-up was ca. $0.58 \mathrm{~J}$.
\end{abstract}

KEYWORDS. Attini; carbon dioxide; Insecta; Formicidae; nest.

The metabolic activity of animals can be defined by three levels: standard, routine and active metabolism. The first corresponds to the basal metabolism or minimal activity of the animal and the second refers to a pattern in which the animals have restricted movements, but are not completely immobilized, and the third (active metabolism) is related to maximal activity, e.g. flight (Prosser 1968).

An interesting example is the active metabolism during the task of cutting in leaf-cutting ant species, whose metabolic rate can increase 31 times when compared to their basal metabolism (Roces \& Ligthon 1995). According to Pielström \& Roces (2013), excavation activity is partitioned among workers into three functionally distinct groups: excavators, that remove soil pellets; short distance carriers, that drop the collected soil pellets after a few centimeters; and long-distance final carriers, that transport the collected soil pellets to the final deposition site. Nest excavation most likely has a high energetic cost to the workers, reflecting the consumption of their body reserves. The energy required for activities of high energetic cost comes from body reserves, body fat (lipid reserves) or hemolymph, such as free carbohydrates (Chown \& Nicolson 2004). The hemolymph contains free sugars, mostly in the form of trehalose, a disaccharide composed of two glucose molecules (Thompson 2003).

It is known that ant workers have a reduction in body reserves during nest excavation, i.e., the soluble carbohydrates are consumed in this activity, while total lipid content remains constant (Camargo et al. 2012). This consumption is a direct consequence of metabolism in the organism, and the method used for its determination is through the rate of expelled carbon dioxide and/or oxygen uptake (Chown \&
Nicolson 2004; Macieira \& Proni 2005). Thus, the goal of this study was to determine the energetic cost of excavation per worker per day, which is readily measured by $\mathrm{CO}_{2}$ production during this activity.

\section{MATERIAL AND METHODS}

Five laboratory colonies of Atta sexdens (Fabricius, 1758) were used to obtain workers for the experiments. Median workers, with the head width between 1.2 to $1.6 \mathrm{~mm}$, were selected since they are responsible for nest excavation (Camargo et al. 2012).

We carried out three independent experiments, in which the workers were confined by $24 \mathrm{~h}, 48 \mathrm{~h}$ or $72 \mathrm{~h}$ (Camargo et al. 2013). All of them followed the same experimental protocol. Thus, groups of 30 workers were confined in a hermetic chamber consisting of an acrylic container measuring $20 \mathrm{~cm}$ in height and $10 \mathrm{~cm}$ in diameter. We choose to use groups because they constitute more live mass than a single worker, and thus, $\mathrm{CO}_{2}$ production could be more readily measured.

In each one of the three experiments we established two treatments: (1) with $\pm 150 \mathrm{~g}$ of soil and (2) without soil for excavation. For each treatment we mounted 10 hermetic chambers. This way we could evaluate the excavation effort by measuring the $\mathrm{CO}_{2}$ production at the presence and absence of soil.

The workers were not fed during the experiment. The soil was sterilized in an oven at $100^{\circ} \mathrm{C}$ for 24 hours to eliminate aerobic microorganisms. The soil used was latosol and was collected at a depth of $60 \mathrm{~cm}$ (soil density $=1.6 \mathrm{~g} / \mathrm{cm}^{3}$; water 
content: 5.4\%) (Stein \& Xavier 1984). The workers' body mass and the soil excavated were measured using an analytical balance. The excavated soil is deposited by ants in the form of pellets, and easily separated from unexcavated soil. A respirometric system was constructed according to Fig. 1. The $\mathrm{CO}_{2}$ sensor used was a Testo model 535 (www.testo.com.br) and the laboratory temperature was maintained at $25^{\circ} \mathrm{C}$.

Consecutive readings $(\mathrm{n}=15)$ of $\mathrm{CO}_{2}$ concentration were performed in the respirometric container and the averages obtained. The results were expressed in ppm and then processed in $\mathrm{mg}$ or $\mathrm{mL}$, using the known volume of the respirometric container B (Fig. 1). It was expected that an increased concentration of $\mathrm{CO}_{2}$ (i.e. $\mathrm{ml} \mathrm{CO} / \mathrm{mg}$ ant mass) would be found when ants were confined with soil to dig. It is known that the ants' respiratory quotient during activity is characteristic of catabolism of body reserves, accounting for $27.6 \mathrm{~J}$ $\mathrm{ml} \mathrm{CO}$ expelled (Roces \& Ligthon 1995), what enabled us to calculate the workers' metabolic cost in Atta sexdens. The concentration of $\mathrm{CO}_{2}\left(\mathrm{ml} \mathrm{CO}_{2} / \mathrm{mg}\right.$ mass ant $)$ and activity energetic cost $(J)$ were analyzed by the Student $t$ test $(\alpha=0.05)$ for each experiment of $24 \mathrm{~h}, 48 \mathrm{~h}$ and $72 \mathrm{~h}$. Weight of the excavated soil at the experiments of 24,48 and $72 \mathrm{~h}$ was compared with an Analysis of Variance. Statistical analyzes were carried out using SigmaPlot.

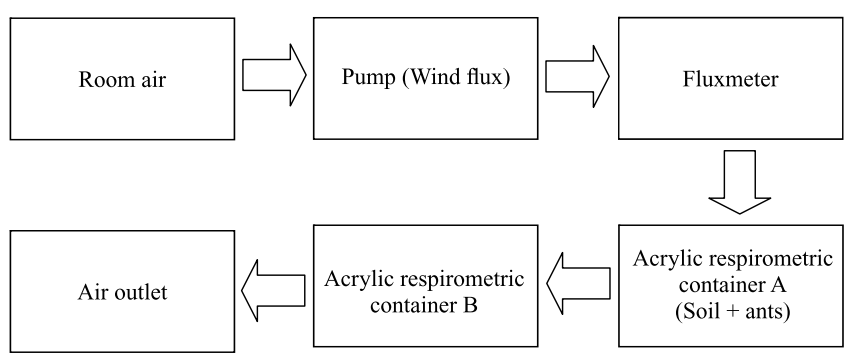

Fig. 1. Respirometric system: acrylic respirometric container A $(10 \mathrm{~cm}$ long x $6 \mathrm{~cm}$ diameter, approximately $282.74 \mathrm{~cm}^{3}$, with soil at the base), with workers. Acrylic respirometric container $\mathrm{B}-\mathrm{CO}_{2}$ sensor. The air is dried by silica gel desiccant.

\section{RESULTS}

As expected, a statistically significant difference in the $\mathrm{CO}_{2}$ concentration was detected within a period of 24 hours ( $\mathrm{t}$ test, $\mathrm{t}=2.144$, $\mathrm{df}=18, \mathrm{p}<0.005$ ). The values were, on average, $2.19 \pm 0.8910^{-3} \mathrm{ml}$ of $\mathrm{CO}_{2} / \mathrm{mg}$ of worker mass for the digging group, and $1.48 \pm 0.5510^{-3} \mathrm{ml}$ of $\mathrm{CO}_{2} / \mathrm{mg}$ of worker mass for non-digging group. The average of $\mathrm{ml}$ of $\mathrm{CO}_{2} / \mathrm{mg}$ of worker mass in 48 hours was $2.85 \pm 1.4410^{-3}$ for the digging group, and $2.48 \pm 0.8810^{-3}$ for the non-digging group, and in 72 hours was $2.71 \pm 1,2310^{-3}$ for the digging group, and $2.38 \pm 0.6510^{-3}$ for the non-digging group. However, there was no difference between the $48 \mathrm{~h}$ excavation ( $\mathrm{t}$ test, $\mathrm{t}=0,696,144, \mathrm{df}=18, \mathrm{p}=0.495)$ and the $72 \mathrm{~h}$ excavation experiments ( $\mathrm{t}$ test, $\mathrm{t}=0.746, \mathrm{df}=18, \mathrm{p}=0.465)$ (Fig. 2).

The average energetic cost $(\mathrm{J})$ per worker in 24 hours was $0.77 \pm 0.31$ for the digging group, and $0.67 \pm 0.12$ for the non-
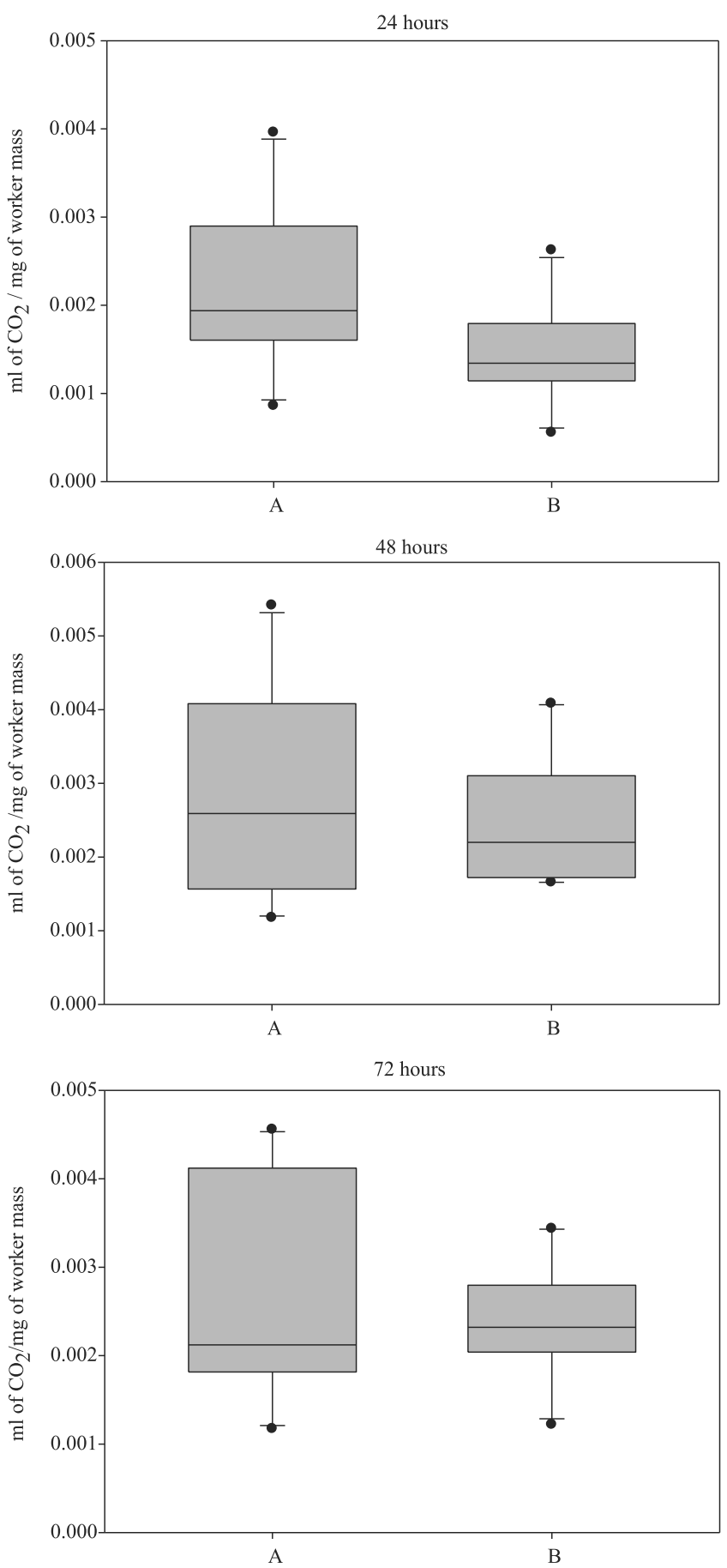

Fig. 2. $\mathrm{CO}_{2}$ concentration ( $\left.\mathrm{ml}\right)$ per worker mass (mg), 24, 48 and 72 hours. A, digging group; B, non-digging group. Data represent mean and standard deviation. The points represent the outliers.

digging group. The energetic cost in the group of workers that excavated, in comparison to the group that did not excavate, differed statistically ( $\mathrm{t}$ test, $\mathrm{t}=2.315, \mathrm{df}=18, \mathrm{p}<0.005$ ). The energetic cost for workers in 48 hours was $0.58 \pm 0.23$ for the digging group, and $0.38 \pm 0.12$ for the non-digging group $(\mathrm{t}$ test, $\mathrm{t}=0.928, \mathrm{df}=18, \mathrm{p}=0.366$ ) and in 72 hours was $0.78 \pm$ 0.41 for the digging group, and $0.66 \pm 0.25$ for the non-digging group ( $\mathrm{t}$ test, $\mathrm{t}=0.740, \mathrm{df}=18, \mathrm{p}=0.469$ ) (Fig. 3). 

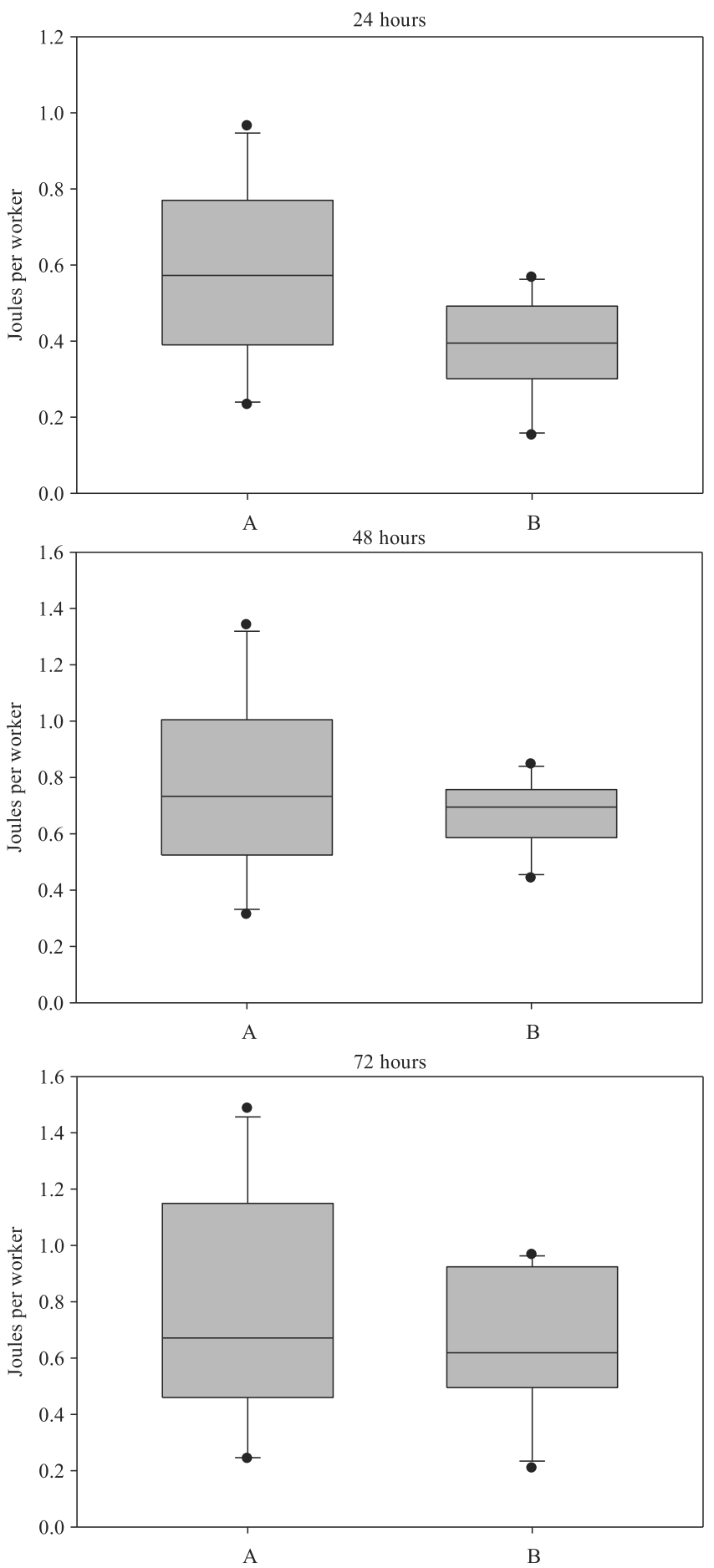

Fig. 3. Energetic cost (J) per worker, 24, 48 and 72 hours. A, digging group; $\mathrm{B}$, non-digging group. Data represent mean and standard deviation. The points represent the outliers.

The average soil weight excavated by workers was 25.50 $\pm 8.05 \mathrm{~g}$ in 24 hours, $26.03 \pm 7.25 \mathrm{~g}$ in $48 \mathrm{~h}$, and $29.13 \pm 6.17$ in 72 hours, indicating that a single worker excavated on average $0.85 \pm 0.27 \mathrm{~g}$ in 24 hours, $0.87 \pm 0.24$ in 48 hours and $0.97 \pm 0.21$ in 72 hours (Fig. 4). These values were not statistically different (ANOVA, $\mathrm{F}_{2,27}=0.66, \mathrm{P}=0.523$ ).

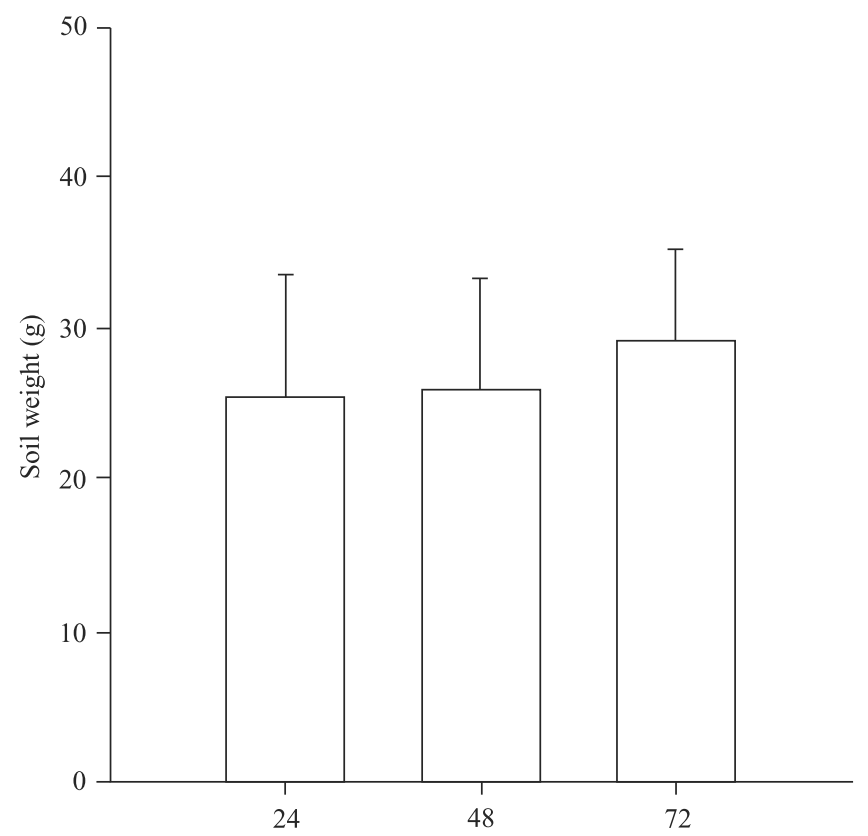

Fig. 4. Average weight of soil (g) dug by workers in 24, 48 and 72 hours. Data represent mean and standard deviation.

\section{DISCUSSION}

As expected, the workers in the digging group produced higher concentrations of carbon dioxide, in comparison to the non-digging group. Interestingly, this production was significant for the $24 \mathrm{~h}$ group, but not for the groups of 48 or 72 $\mathrm{h}$. As a consequence, the amounts of expended energy were also different for the experimental groups of $24 \mathrm{~h}$, but not for 48 or $72 \mathrm{~h}$. These results are probably related to the digging rate per time. This activity pattern of excavation was also observed in Acromyrmex lundi (Guérin-Méneville, 1838) (Fröhle \& Roces 2009) and in other species (Buhl et al. 2004).

It is probable that a reduction of $\mathrm{O}_{2}$ concentration occurred during 24, 48 and 72 hours leading to hypoxic conditions. On the other hand, increased $\mathrm{CO}_{2}$ concentration will have resulted in hypercapnia. Worker ants, however, are known to tolerate high levels of $\mathrm{CO}_{2}$, particularly workers of Atta, which can withstand severe hypoxia (Hebling et al. 1992) and also behave normally at high concentrations of $\mathrm{CO}_{2}$, as found in nests of $A$. capiguara Gonçalves, 1944 and A. laevigata (Smith, 1858) of about 15 to $45 \%$ (Bollazzi et al. 2012). Additional examples also come from ant species that inhabit mangrove swamps, in which levels of $\mathrm{CO}_{2}$ inside the nests during nest closure reach $11 \%$ (Nielsen et al. 2003). Under hypercapnic and hypoxic conditions, ants are able to support aerobic respiration up to $15 \%$ of $\mathrm{CO}_{2}$ concentrations (Nielsen et al. 2006; Nielsen \& Christian 2007). On average, the volume of $\mathrm{CO}_{2} \mathrm{~mL} \mathrm{~g}^{-1}$ produced was $2.19 \pm 0.9$ for the digging group and $1.48 \pm 0.6$ for the non-digging group. These values are low in comparison to other insects and other activities, e.g., $9.1 \mathrm{~mL} \mathrm{CO}_{2} \mathrm{~h}^{-1} \mathrm{~g}^{-1}$ for Camponotus rufipes (Fabricius, 1775) during foraging (Schilman \& Roces 2008) and $55 \mathrm{~mL} \mathrm{CO}_{2} \mathrm{~h}^{-1} \mathrm{~g}^{-1}$ for honey bees during flight (Blatt \& 
Roces 2001). It is probable that in the present case, digging behaviour was not so energetically costly, because the workers remained sealed with only a small amount of soil, with standard density and moisture.

In natural conditions, workers of Atta sexdens build very large nests with chambers up to $6 \mathrm{~m}$ deep in mature colonies, making excavation extremely energetically costly for the colony (Camargo \& Forti 2013). Additionally, the intense digging effort can negatively affect the survival of the queens of Atta sexdens during nest founding (Carmargo et al. 2011).

In a study with leaf-cutting ants, Camargo et al. (in press) found that the soluble sugar concentrations in workers were reduced to $5.82 \mu . \mathrm{mg}^{-1}(20.42 \%)$ by $24 \mathrm{~h}$ of digging, in comparison to non-digging ants $\left(28.5 \pm 4.29 \mu . \mathrm{mg}^{-1}\right)$. It is known that catabolism of $1 \mathrm{mg}$ of carbohydrate provides about 17.1 J of energy (Randall et al. 2002), so the energetic cost of digging is therefore $0.1 \mathrm{~J} \mathrm{mg}^{-1}$ per ant. The average mass of a worker ant used in this study was of $9.65 \pm 1.50 \mathrm{mg}$, i.e., $0.96 \mathrm{~J}$ per worker in a digging group, for 24 hours.

When the average $\mathrm{CO}_{2}$ produced was calculated (27.6 J per $\mathrm{ml}$ of $\mathrm{CO}_{2}$ expelled; Roces \& Ligthon 1995), an average of $0.58 \pm 0.23 \mathrm{~J}$ per worker was found (Fig. 3), similar to the above estimate in spite of the different methods that were used. Additionally, a single worker dug on average $0.85 \pm$ $0.27 \mathrm{~g}$ in 24 hours, 0.87 in 48 hours \pm 0.24 and $0.97 \pm 0.21$ in 72 hours, similar to values found by Camargo et al. (2012), which reported $0.56 \mathrm{~g}$ per worker. Therefore, a worker with body mass of $9.65 \pm 1.50 \mathrm{mg}$ dug in average $0.85 \pm 0.27 \mathrm{~g}$ of soil in 24 hours, consuming ca. $0.58 \pm 0.23 \mathrm{~J}$, a value representing a significant energetic cost to ant workers.

\section{ACKNOWLEDGEMENTS}

The first author is grateful to CNPq for a postdoctoral grant. The authors also thank São Paulo State Research Foundation (FAPESP) (2007/04010-0 and 2007/07091-0). Lopes thanks Fapemig for financial support (APQ 00342-12).

\section{REFERENCES}

Blatt, J. \& Roces, F. 2001. Haemolymph sugar levels in foraging honey bees (Apis mellifera carnica): dependence on metabolic rate and in vivo measurement of maximal rates of trehalose synthesis. Journal of Experimental Biology 204: 2709-2716.

Bollazzi, M., Forti, L.C. \& Roces, F. 2012. Ventilation of the giant nests of Atta leaf-cutting ants: does underground circulating air enter the fungus chambers? Insectes Sociaux 59: 487-498.

Buhl, J., Gautrais, J., Deneubourg, J.L. \& Theraulaz, G. 2004. Nest excavation in ants: group size effects on the size and structure of tunneling networks. Naturwissenschaften 91: 602-606.
Camargo, R.S. \& Forti, L.C. 2013. Queen lipid content and nest growth in the leaf cutting ant (Atta sexdens rubropilosa) (Hymenoptera: Formicidae). Journal of Natural History 47: 65-73.

Camargo, R.S., Forti, L.C., Fujihara, R.T. \& Roces, F. 2011. Digging effort by leaf-cutting ant queens (Atta sexdens rubropilosa) and its effects on survival and colony growth during the claustral phase. Insectes Sociaux 58: 17-22.

Camargo, R.S., Fujihara, R.T. \& Forti, L.C. 2012. Nest digging by leafcutting ants: Effect of group size and functional structures. Psyche 2012, 4p. doi: 10.1155/2012/426719.

Camargo, R.S., Lopes, J.F.S. \& Forti L.C. 2013. O jardim de fungo atua como um molde para a construção das câmaras em formigas cortadeiras? Ciência Rural 43: 565-570.

Camargo, R.S., Lopes, J.F.S., Forti L.C., Somera, A.F. \& Bacci, M. in press. Energy substrate used by workers of leaf-cutting ants during nest excavation. Revista Brasileira de Entomologia.

Chown, S.L. \& Nicolson, S.W. 2004. Insect physiological ecology: mechanisms and patterns. Oxford University Press, $254 \mathrm{p}$.

Fröhle, K. \& Roces, F. 2009. Underground agriculture: the control of nest size in fungus-growing ants, p. 95-104. In: Theraulaz, G., Solé, R \& Kuntz, P. (eds.). From insect nest to human architecture. Venice, European Centre for Living Technology.

Hebling M.J.A., Penteado, C.H.S. \& Mendes, E.G. 1992. Respiratory regulation in workers of the leaf-cutting ant Atta sexdens rubropilosa Forel, 1908. Comparative Biochemistry Physiology 101: 319-322.

Macieira, O.J.D. \& Proni, E.A. 2005. Influência da temperatura na taxa respiratória de abelhas forrageiras Trigona spinipes (Fabricius) (Hymenoptera, Apidae, Meliponina) durante períodos de verão e inverno. Revista Brasileira Zoologia 22: 1159-1163.

Nielsen, M.G. \& Christian, K.A. 2007. The mangrove ant, Camponotus anderseni, switches to anaerobic respiration in response to elevated $\mathrm{CO}_{2}$ levels. Journal of Insect Physiology 53: 505-508.

Nielsen, M.G., Christian, K. \& Birkmose, D. 2003. Carbon dioxide concentrations in the nests of the mud-dwelling mangrove ant Polyrhachis sokolova Forel (Hymenoptera: Formicidae). Australian Journal of Entomology 42: 357-362.

Nielsen, M.G., Christian, K., Henriksen, P.G. \& Birkmose, D. 2006. Respiration by mangrove ants Camponotus anderseni during nest submersion associated with tidal inundation in Northern Australia. Physiological Entomology 31: 120-126.

Pielström, S. \& Roces, F. 2013. Sequential soil transportation and its influence on the spatial organisation of collective digging in leafcutting ants. PloSONE 8: e57040.

Prosser, C.L. 1968. Temperatura, p. 256-306. In: Prosser, C.L. \& Brown Jr., F.A. (eds.). Fisiologia Comparada. México, Editora Interamericana, $966 \mathrm{p}$.

Randall, D.J., Burggren W.W. \& French F. 2001. Eckert animal physiology: mechanisms and adaptations. New York, W.H. Freeman, 752 p.

Roces, F. \& Lighton, J.R.B. 1995. Larger bites of leaf-cutting ants. Nature 373: 392 .

Schilman, P.E. \& Roces, F. 2008. Haemolymph sugar levels in a nectarfeeding ant: dependence on metabolic expenditure and carbohydrate deprivation. Journal of Comparative Physiology B 178: 157-165.

Stein, C. \& Xavier, G.F. 1984. Does substrate density affect the nest depth of female Atta sexdens rubropilosa (Forel, 1908) (Hymenoptera: Formicidae). Brazilian Journal of Medical Research 17: 297-300.

Thompson, S.N. 2003. Trehalose - The insect "Blood" sugar. Advances in Insect Physiology 31: 205-285. 